\title{
Arachidonic and eicosapentaenoic acids induce oxidative stress to suppress proliferation of human glioma cells
}

\author{
Anasuya Devi Hari ${ }^{1}$, Naidu G. Vegi², Undurti N. Das ${ }^{3}$
}

\author{
${ }^{1}$ BioScience Research Centre, GVP College of Engineering Campus, Visakhapatnam, \\ India \\ ${ }^{2}$ NIPER, Hyderabad, India \\ ${ }^{3}$ UND Life Sciences, USA
}

Submitted: 21 June 2018

Accepted: 20 July 2018

Arch Med Sci 2020; 16 (4): 974-983

DOI: https://doi.org/10.5114/aoms.2020.92293

Copyright $\odot 2020$ Termedia \& Banach

\section{Introduction}

The most malignant tumor of the brain is glioblastoma multiforme (commonly called gliomas). Despite debulking surgery, radiation and chemotherapy, the survival of patients diagnosed to have glioblastoma multiforme is not more than 44 weeks. Gliomas are difficult to treat, partly because while growing they merge with normal brain tissue and hence during surgery it is difficult to delineate the tumor tissue from normal brain tissue to excise them completely. In view of this, developing newer therapeutic strategies that target glioma cells selectively with minimal toxicity to normal brain cells is urgently needed. Previous studies performed by us and others revealed that polyunsaturated fatty acids (PUFAs), especially $\gamma$-linolenic acid (GLA, 18:3 n-6), arachidonic acid (AA, 20:4 n-6), eicosapentaenoic acid (EPA, 20:5n-3) and docosahexaenoic acid (DHA, 22:6 n-3), have selective tumoricidal action and induce apoptosis of glioma cells both in vitro and in vivo [1-7].

Previous studies revealed that many tumor cells have decreased expression of $\Delta^{6}$ and $\Delta^{5}$ desaturases that are essential for the formation of long-chain metabolites of dietary essential fatty acids (EFAs): linoleic (LA, 18:2 n-6) and $\alpha$-linolenic (ALA, 18:3n-3) acids. This decrease in the activity of desaturases results in a deficiency of long-chain metabolites of EFAs such as GLA, dihomo-GLA (DGLA, 20:3 n-6), AA formed from LA and EPA and DHA from ALA in the tumor cells, possibly to protect themselves (tumor cells) from the cytotoxic action of PUFAs, free radicals (generated during the metabolism of EFAs/PUFAs) and lipid peroxides derived from various PUFAs [reviewed in 8,9 ]. In a previous preliminary open label clinical study, we showed that intratumoral infusion/injection of GLA regresses glioblastoma [3, 4, 6] suggesting that some PUFAs can be exploited for the therapy of cancer including gliomas. This assumption is supported by the studies performed in cell cultures, rodent glioma and other tumor models, and preliminary human studies [1-19].

The tumoricidal action of various PUFAs has been attributed to their ability to enhance free radical generation and lipid peroxides specifically in tumor cells, changes in the lipid content of the cell membrane due to the incorporation of supplemented PUFA, action on anti-angiogenic factors and enzymes involved in lipid metabolism, changes in P-gly-

\author{
Corresponding author: \\ Undurti N. Das MD, DSc, \\ FAMS, FRSC \\ UND Life Sciences

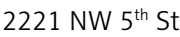 \\ 98604, Battle Ground, USA \\ Phone: 2162315548 \\ E-mail: undurti@hotmail.com
}


coprotein expression and induction of changes in mitochondrial function [1-19]. It is known that the expression of different oncogenes differently affects sensitivity and/or resistance of various cancer cells to the cytotoxic action of anti-cancer drugs $[17,18]$. In a previous study [20], we showed that AA produces its tumoricidal action on IMR-32 (human neuroblastoma) cells by enhancing the expression of FAS and caspases 3 and 8 compared to the control, indicating the involvement of the extrinsic apoptotic pathway [21]. However, it is not known whether the same mechanism plays a role in the induction of death of other human-derived neuroblastoma cells in the presence of PUFAs. Hence, we performed the present study to explore this possibility by studying the effect of various PUFAs on two different human glioma cells (LN229, HNGC2) in vitro.

The results of this study revealed that $A A$ and EPA suppress p53, Ras, Myc, BCL-2/Bax, NF-кB/ $/ \kappa B$ and 5-LOX and enhance cytochrome $C$ and caspases 3 and 9 expression secondary to an increase in the accumulation of lipid peroxides and thus inhibit tumor cell growth.

\section{Material and methods}

\section{Chemical reagents}

Cell culture compounds including DMEM high glucose culture medium (Cat. No: 12100-046) and heat inactivated fetal bovine serum from Gibco (Cat. No: 16000-044) were obtained from Incell technologies Pvt. Ltd, India; penicillin - streptomycin (Cat. No: P0781), amphotericin (Cat. No: A2942), trypsin EDTA (Cat. No: T4049), MTT (Cat. No: M5655), COX (Cat. No: 17378) and LOX (Cat. No: 74540) inhibitors, RTq-PCR (Cat. No: 1318855) components were from Sigma Aldrich Pvt. Ltd (Bangalore, India); primers from Bioserve Hyderabad, India. All fatty acids were procured from Cayman Chemical Company (California, USA).

\section{Cell culture conditions}

Glioblastoma cell lines LN229 and HNGC2 were obtained from the Centre for Cellular and Molecular Biology (CCMB) Hyderabad, India. Both the cell lines were subcultured in DMEM ( $\mathrm{pH} 7.4$ ) medium containing $\mathrm{NaHCO}_{3}, 100 \mathrm{U} / \mathrm{ml}$ penicillin, $100 \mu \mathrm{g} / \mathrm{ml}$ streptomycin, $1.25 \mu \mathrm{g} / \mathrm{ml}$ amphotericin B and $10 \%$ fetal bovine serum (FBS). Cells seeded in vented flasks $\left(T 25 \mathrm{~cm}^{2}\right)$ in which they grew as a monolayer in humidified $5 \% \mathrm{CO}_{2}$ ambience at $37^{\circ} \mathrm{C}$. On reaching $80 \%$ confluence, the cells were washed with phosphate buffered saline (PBS, pH 7.4) and trypsinized (trypsin $-0.25 \%$, EDTA $-0.02 \%$ ) for $2-3 \mathrm{~min}$. Trypsin was inactivated using FBS. The cells obtained by centrifugation were tested for their viability using the trypan blue dye exclusion method by counting the cells in a hemocytometer. The pellets of cells obtained were passaged and used for further experimental studies $[19,20]$.

\section{Cell proliferation assay}

\section{Effect of various fatty acids on glioma cells}

Glioma cells LN229 and HNGC2 were seeded at a density of $5 \times 10^{3}$ cells $/ 100 \mu \mathrm{l} /$ well in 96-well culture plates. The cells were allowed to attach for $24 \mathrm{~h}$ and supplemented with fresh medium and used for further studies.

\section{Effect of n-6 and n-3 PUFAs on growth of glioma cells}

Glioma cells LN229 and HNGC2 were seeded at a density of $5 \times 10^{3}$ cells $/ 100 \mu \mathrm{l} /$ well in 96 -well culture plates and allowed to attach for $24 \mathrm{~h}$. At the end of the attachment period, cells were treated with different doses of $(10,20,30 \mu \mathrm{g} / \mathrm{ml}) \mathrm{n}-6$ and $\mathrm{n}-3$ PUFAs and incubated for $24 \mathrm{~h}$. Cell viability was evaluated at the end of the incubation period by MTT assay as described previously [22-24].

\section{Effect of COX and LOX inhibitors on AA/ EPA-induced changes in proliferation of glioma cells}

Since both AA and EPA form precursors to various prostaglandins, thromboxanes, leukotrienes, lipoxin A4 (from AA) and resolvins (from EPA), we next studied whether COX and LOX inhibitors can influence the actions of AA and EPA on the proliferation of glioma cells LN229 and HNGC2. For this purpose the cells were seeded at a density of $5 \times$ $10^{3}$ cells $/ 100 \mu \mathrm{l} /$ well in 96-well culture plates and allowed to attach for $24 \mathrm{~h}$ at the end of which they were treated with different doses of COX and LOX inhibitors (indomethacin and NDGA respectively) in the presence of AA/EPA $[19,20]$.

\section{Effect of AA/EPA on lipid peroxides and nitric oxide}

Glioma cells were seeded in 24-well plates at a density of $1 \times 10^{5}$ cells per $\mathrm{ml}$ of culture medium per well and allowed to attach for $24 \mathrm{~h}$ before the treatment. After the attachment period, cells were treated with AA/EPA $(30 \mu \mathrm{g} / \mathrm{ml})$ as representative of $n-6$ and $n-3$ fatty acids respectively for $24 \mathrm{~h}$. After the treatment period, spent medium was collected and cells were washed with $500 \mu \mathrm{l}$ of PBS ( $\mathrm{pH}$ 7.4). Washed cells were lysed with NET lysis buffer. Lipid peroxides and nitric oxide levels were measured in both the cell lysates and supernatants as described previously [19, 20]. 


\section{Effect of AA/EPA on antioxidant enzymes}

For this study, LN229, HNGC2 cells were seeded in a 24-well plate at a density of $1 \times 10^{5}$ cells per $\mathrm{ml}$ of culture medium per well. The cells were allowed to attach for $24 \mathrm{~h}$ before the treatment. After the attachment period, cells were treated for $24 \mathrm{~h}$ with AA/EPA $(10,20$ and $30 \mu \mathrm{g} / \mathrm{ml})$. At the end of the treatment period, spent medium (supernatant) was collected and used for various estimations. Cells were washed using $500 \mu \mathrm{l}$ of PBS ( $\mathrm{pH} 7.4)$ and were lysed using NET lysis buffer. Antioxidant enzymes - superoxide dismutase, catalase, glutathione-s-transferase and glutathione peroxidase - were measured in both the supernatants and cell lysates [19, 20].

Previously, we performed dose- and time-dependent studies with n-6 (LA, GLA, DGLA and AA) and $n-3$ (ALA, EPA and DHA) on the proliferation of LN229 and HNGC2 cell in vitro using MTT assay. In this study, the two glioma cell lines were exposed to $10-50 \mu \mathrm{g} / \mathrm{ml}(10,20,30,40,50 \mu \mathrm{g} /$ $\mathrm{ml}$ ) of PUFAs for 24 and $48 \mathrm{~h}$. The results of this study showed that all PUFAs have the ability to decrease the proliferation of LN229 and HNGC2 cells in vitro. Furthermore, it was observed that a $30 \mu \mathrm{g} / \mathrm{ml}$ dose of both $\mathrm{n}-6$ and $\mathrm{n}-3$ PUFAs at the end of $24 \mathrm{~h}$ of the incubation produced an $\sim 50 \%$ decrease in proliferation $(p<0.05)$ compared to the control (see Figures $1 \mathrm{~A}$ and $\mathrm{B}$ for results obtained with 10, 20 and $30 \mu \mathrm{g} / \mathrm{ml}$ of PUFAs tested). In view of these results, in the present study a $30 \mu \mathrm{g} / \mathrm{ml}$ dose of AA and EPA and incubation for a $24 \mathrm{~h}$ period were employed. Furthermore, we used in all subsequent studies only AA and EPA as representative of $n-6$ and $n-3$ fatty acids.

\section{Molecular gene expression studies}

\section{RNA isolation}

Glioma cells were seeded at a density of $2 \times 10^{6} /$ $\mathrm{ml} /$ well in 6-well culture plates and were used for RNA extraction. After the initial attachment period, glioma cells were treated with AA/EPA (30 $\mu \mathrm{g} /$ $\mathrm{ml}$ ) for $24 \mathrm{~h}$. At the end of the incubation period, TRIzol reagent method was employed to isolate RNA. Quantification and purity of the RNA sample were tested by spectrophotometer (Biochrome libra S70, J.L. Tech, Hyderabad, India). 1 g of RNA/ sample/well was loaded on $1.5 \%$ agarose gel to check the integrity of the sample.

\section{C-DNA synthesis (semi-quantitative RT-PCR)}

To study various gene expression levels, C-DNA synthesis was performed using SuperScript FirstStrand for qRT-PCR. C-DNA was amplified using specific primers by PCR (Eppendorf thermocycler-5331; USA). Human $\beta$-actin was chosen as the active con- trol. The expression of various genes was measured by qRT-PCR as described previously (ref. BBRC). On the completion of PCR, products of each gene processed were separated by means of an electric field at $100 \mathrm{~V}$ and size on $1.5 \%$ agarose gels in $1 \times$ TAE buffer, stained with ethidium bromide. The following primer pairs from $5^{\prime}-3^{\prime}$ were used respectively: $\beta$-actin - 243 bps: F:CGTGGGCCGCCCTAGGCACCA R: TTGGCCTTAGGGTTCAGGGGGG.

Bax - 367 bps: F: ACCAAGAAGCTGAGCGAGTGTC, R: ACAAAGATGGTCACGGTCTGCC.

BCl2 - 319 bps: F: CGACGACTTCTCCCGCCGCTAC$\mathrm{CGC}$,

R: CCGCATGCTGGGGCCGTACAGTTCC.

P53 - 293 bps: F: CAGCCAAGTCTGTGACTTGCACGTAC,

R: CTATGTCGAAAAGTGTTTCTGTCATC.

Cyt C - 242 bps: F: GCGTGTCCTTGGACTTAGAG, R: GGCGGCTGTGTAAGAGTATC.

Casp9 - 325 bps: F: GGTTCTGGAGGATTTGGTGA, R: GACAGCCGTGAGAGAGAATGA.

Casp3 - 378 bps: F: AGAAGATCACAGCAAAAGGAGC, R: TCAAGCTTGTCGGCATACTG.

NF-kB - 300 bps: F: AGCACAGATACCACCAAGACCC, R: CCCACGCTGCTCTTCTATAGGAAC.

IKB - 68 bps: F: TTGGGTGCTGATGTCAATGC, R: AGGTCCACTGCGAGGTGAAG.

Ras - 164 bps: F: TGGAGTCGTAGGACCCTGA, R: TGGTGTTCTGATAAGGCCCC.

Myc - 19 5bps: F: CGACCACAAGGCCCTCAGTA, R: CAGCCTTGGTGTTGGAGGAG.

Fos - 236 bps: F: GAATAAGATGGCTGCAGCCAAATGCCGCAA,

R: CAGTCAGATCAAGGGAAGCCACAGACATCT.

COX-I - 494bps: F: GTTCAACACCTCCATGTTGGTGGAC,

R: TGGTGTTGAGGCAGACCAGCTTC. COX-II - 558bps: F: GTCTGATGATGTATGCCACAATCTG,

R: ATGCCAGTGATAGAGGGTGTTAAA.

5-LOX - 327 bps: F: ATCAGGACGTTCACGGCCGA, R: GTCCACGATCTGCTCAATGGT.

PCR cycling conditions: denaturation at $94^{\circ} \mathrm{C}$ for $30 \mathrm{~s}$, annealing at $52.5^{\circ}, 63^{\circ}, 67^{\circ}, 57^{\circ}, 62^{\circ}, 62^{\circ}$, $61^{\circ}, 62^{\circ}, 68^{\circ}, 57^{\circ}, 58^{\circ}, 74^{\circ}, 63^{\circ}, 64^{\circ}, 57^{\circ}$ for $30 \mathrm{~s}$ respectively to the above-mentioned gene sequences and extension at $72^{\circ}$ for 2 min, 36 cycles were carried out for amplification. Observed bands for specific genes on the gel were photographed by a gel documentation system which has an UV light trans-illuminator hood and a camera for image capturing. All the genes were quantified using image analysis software (Gel documentation unit, Major science, J.L. Tech, Hyderabad, India).

\section{Statistical analysis}

All the above experiments were repeated twice on two different occasions. The data values 
A

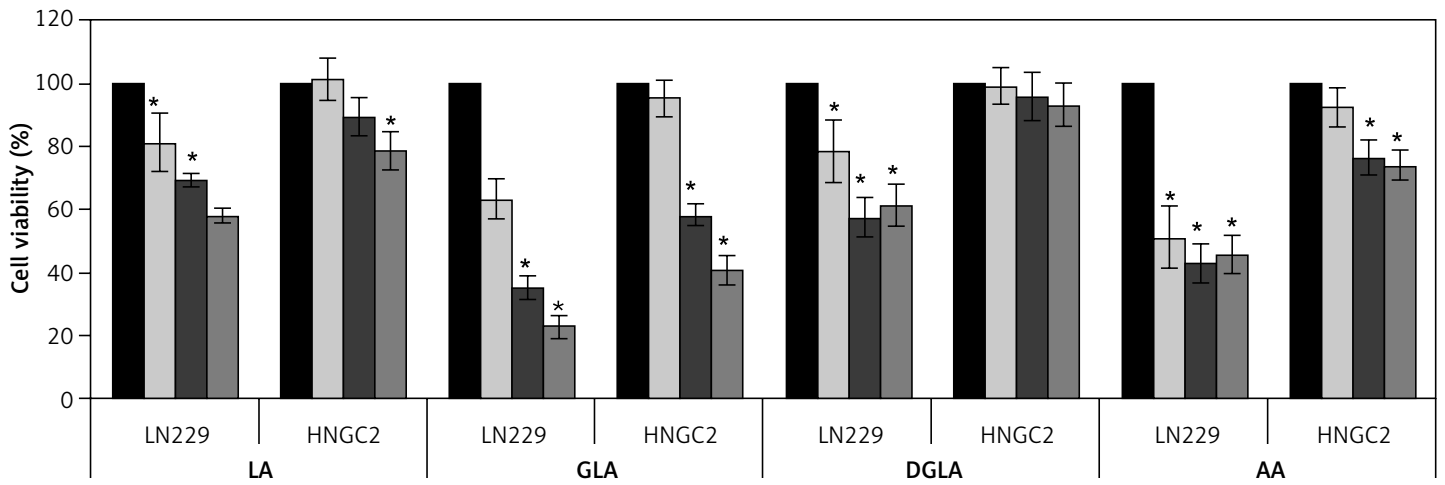

B

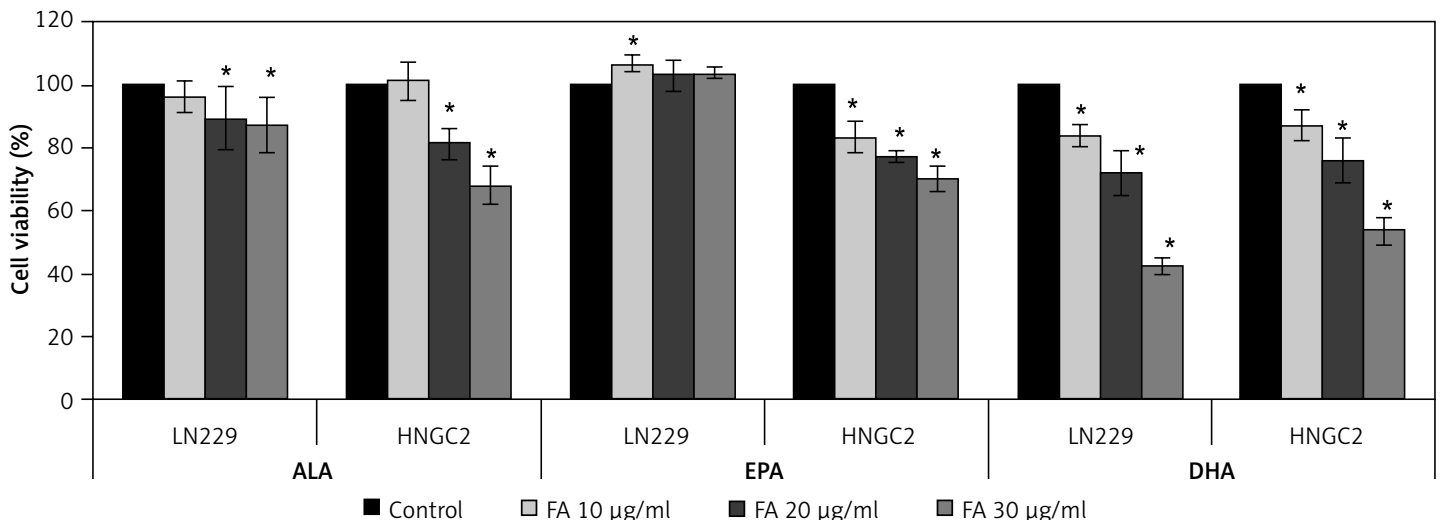

C

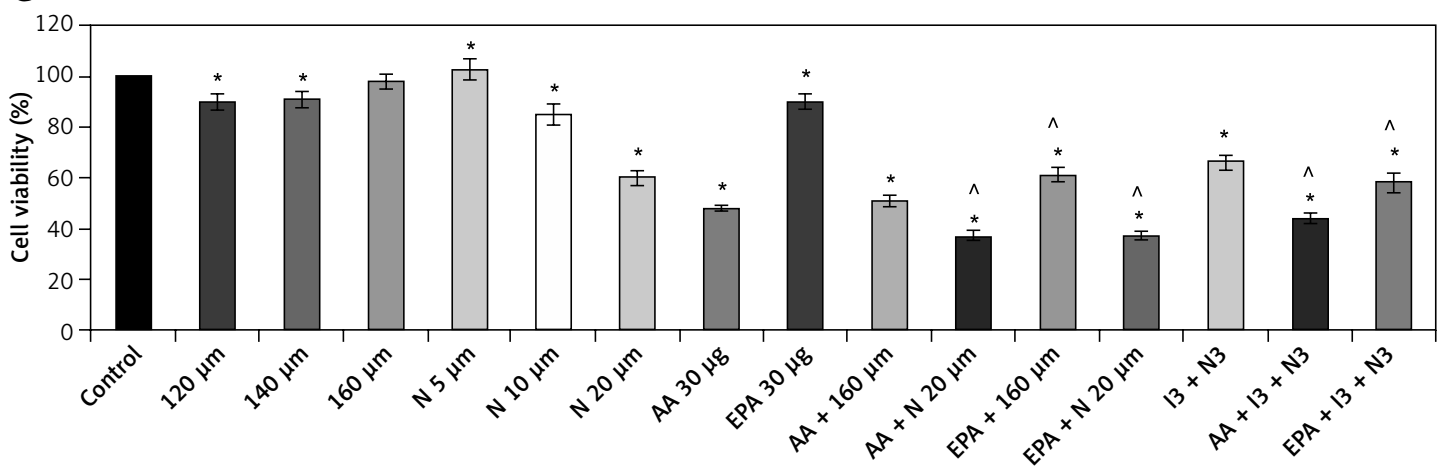

D

LN229

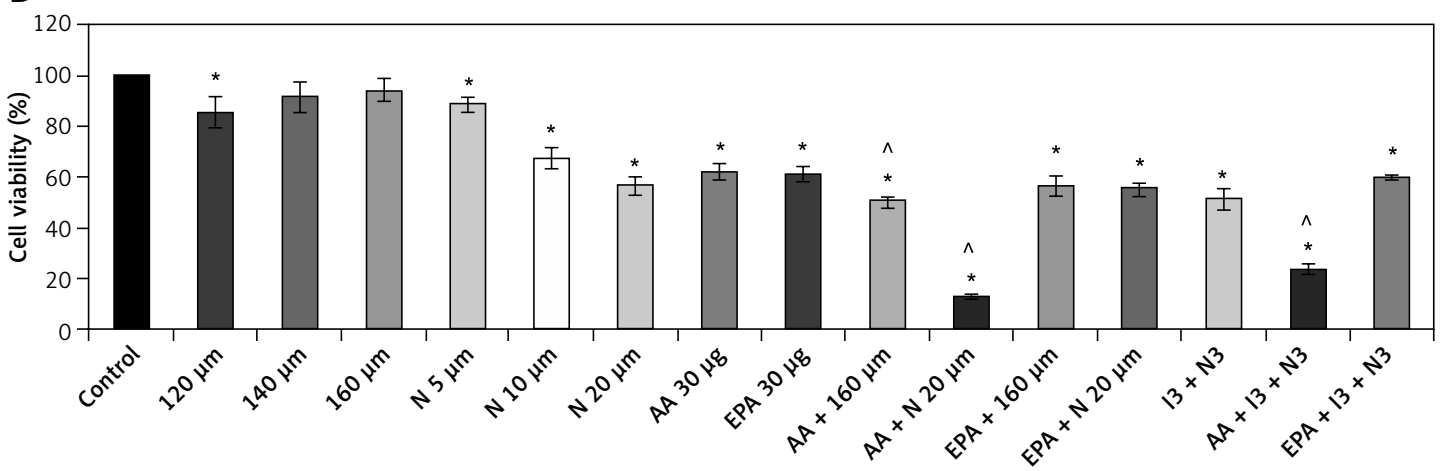

HNGC2

Figure 1. Effect of n-6, n-3 PUFAs on LN229 and HNGC2 cells: LN229/HNGC2 cells $\left(1 \times 10^{4} / 100 \mu \mathrm{l}\right)$ were exposed to different doses of n-6 PUFAs, n-3 PUFAs, and incubated for $24 \mathrm{~h}$. At the end of the treatment period, cell viability was measured by MTT assay. A - LN229/HNGC2 cells treated with n-6 PUFAs (10, 20, 30 Mg/ml). B - LN229/ HNGC2 cells treated with $\mathrm{n}-3$ PUFAs $(10,20,30 \mu \mathrm{g} / \mathrm{ml})$. All values are expressed as mean $\pm \mathrm{SEM}, n=6 .{ }^{\star} P<0.001$, compared to control; C - Effect of COX and LOX inhibitors indomethacin and NDGA respectively on growth of LN229/HNGC2 cells. $\wedge p<0.05$ - compared to respective fatty acid treated (AA/EPA) groups. D - Effect of COX/LOX inhibitors \pm AA/EPA on growth of LN229/HNGC2 cells in vitro

C - control, FA - fatty acids, AA - arachidonic acid, LA - linoleic acid, GLA - $\gamma$-linolenic acid, DGLA - dihomo gamma linolenic acid, $E P A-e i c o s a p e n t a e n o i c ~ a c i d, D H A-d o c o s a h e x a e n o i c ~ a c i d, A L A-\alpha$-linolenic acid. 
showed reproducible results when observed and are expressed as mean \pm SEM. To evaluate the significance of differences between the mean values by paired $T$-test, data were statistically analyzed using the MS Excel statistical analysis tool.

\section{Results}

\section{Cell viability assay}

Effect of n-6 and n-3 PUFAs on proliferation of glioma cells

When LN229 glioma cells were treated with $10,20,30 \mu \mathrm{g} / \mathrm{ml}$ of $\omega-6$ (LA, GLA, DGLA and AA) and $\omega-3$ PUFAs (ALA, EPA and DHA), all PUFAs produced a significant dose-dependent reduction in cell proliferation. Among n-6 PUFAs, LA/GLA/AA $(30 \mu \mathrm{g} / \mathrm{ml})$ and among $\mathrm{n}-3$, EPA/DHA $(30 \mu \mathrm{g} / \mathrm{ml})$ showed maximum growth inhibitory action. On the other hand, GLA $(30 \mu \mathrm{g} / \mathrm{ml})$ and DHA $(30 \mu \mathrm{g} /$ $\mathrm{ml}$ ) exerted maximum growth inhibitory action on HNGC2 cells (Figures $1 \mathrm{~B}$ and C). Of all the fatty acids tested, GLA is the most effective growth inhibitory fatty acid on the glioma cells studied. However, we selected AA and EPA for further studies since they form precursors to various eicosanoids and are also able to produce a significant reduction in the proliferation of both the glioma cells studied. It may be mentioned here that PUFAs induced apoptosis of the glioma cells tested (data not shown).

\section{Effect of COX and LOX inhibitors on proliferation of glioma cells}

We next studied the effect of the COX inhibitor indomethacin and the LOX inhibitor NDGA on the growth of glioma cells in vitro. These studies revealed, in both the glioma cells studied, that the COX inhibitor indomethacin $(20,40,60 \mu \mathrm{g} / \mathrm{ml})$ by itself did not have any action on the proliferation while the LOX inhibitor NDGA suppressed the proliferation of LN229 and HNGC2 cells in vitro. In contrast, both indomethacin and NDGA did not have any effect on the growth inhibitory action of AA and EPA on LN229 and HNGC2 cells. In fact, surprisingly, when the glioma cells were supplemented with indomethacin + NDGA + AA/EPA enhanced suppression of growth inhibitory action of AA/EPA was noted (Figures $1 \mathrm{C}$ and $\mathrm{D}$ ). These results imply that COX metabolites may not have much significant action on the growth of glioma cells studied. To verify this possibility, we next studied the effect of various prostaglandins and LTD4 and LTE4 $(10,50$ and $100 \mathrm{ng} / \mathrm{ml})$ on the growth of LN229 and HNGC2 cells in vitro. These results showed that all the prostaglandins tested (PGE1, PGE2, PGI2, PGF2) and leukotrienes (LTD4 and LTE4) suppressed the growth of LN229 and HNGC2 by not more than $10-25 \%$, which barely showed significance compared to the control (data not shown). These results suggest that, possibly, eicosanoids have insignificant action on the growth of LN229 and HNGC2 cells in vitro. Based on these results, we suggest that the growth inhibitory actions of AA and EPA on LN229 and HNGC2 cells noted may be due to the fatty acids themselves with little or no involvement of eicosanoids.

\section{Biochemical assays}

\section{Effect of AA/EPA on formation of lipid peroxides and nitric oxide}

The results of these studies showed that both nitric oxide and lipid peroxides were increased in the supernatants and cell lysates of glioma cells in the presence of AA/EPA thus can augment oxidative stress in glioma cells (LN229 > HNGC2, Table I). It is evident that the total levels of lipid peroxides (LPO) (supernatant + cell lysate) were significantly elevated in LN229 cells in the presence of both AA and EPA. However, in the HNGC2 cells AA treatment did not produce any significant increase in the production of lipid peroxides (both in the supernatant and cell lysate) compared to the control. On the other hand, EPA did induce a significant increase in lipid peroxides in both the supernatant and cell lysate compared to the control.

\section{Effect of AA/EPA on antioxidant enzymes in glioma cells}

The results of the studies performed with AA/ EPA revealed that both $A A$ and EPA produced a significant increase in the activity of catalase, SOD, glutathione-s-transferase and glutathione peroxidase when compared to the control. These results suggest that AA/EPA produce significant changes in the antioxidant defenses of glioma cells (LN229 > HNGC2) (Table I B).

\section{Gene expression studies (semi-quantitative RT-PCR)}

\section{Effect of AA $(30 \mu \mathrm{g} / \mathrm{ml}) /$ EPA $(30 \mu \mathrm{g} / \mathrm{ml})$ on mRNA expression of various genes}

It is known that the apoptotic signaling pathway consists of an extrinsic (death receptor pathway) and an intrinsic component (mitochondrial pathway) [25]. Bcl-2 family proteins play a vital role in the survival of cells by acting on the caspases of the intrinsic pathway. In view of this, we studied the effect of AA/EPA on the expression of $B C L-2$ and caspases and other factors that influence cell proliferation and apoptosis.

These results revealed that both the glioma cells treated with AA and EPA produced a significant 
Table I. Effect of AA/EPA $(30 \mathrm{\mu g} / \mathrm{ml})$ on nitric oxide and lipid peroxides production and antioxidant enzymes in LN229 and HNGC2 cells. Both the glioma cells were treated with AA/EPA $(30 \mu \mathrm{g} / \mathrm{ml})$ and incubated for $24 \mathrm{~h}$. At the end of treatment, spent medium was collected and cells were lysed. A - Both cell lysate and spent medium were used for measurement of nitric oxide and lipid peroxides. B - Cell lysate was used for measurement of anti-oxidant enzymes

A

\begin{tabular}{|c|c|c|c|c|c|c|}
\hline \multirow[t]{2}{*}{ Parameter } & \multicolumn{3}{|c|}{ LPO $[\mu \mathrm{M}]$} & \multicolumn{3}{|c|}{$\mathrm{NO}[\mu \mathrm{M}]$} \\
\hline & Supernatant & Lysate & $\begin{array}{c}\text { Lysate + } \\
\text { supernatant }\end{array}$ & Supernatant & Lysate & $\begin{array}{c}\text { Lysate }+ \\
\text { supernatant }\end{array}$ \\
\hline \multicolumn{7}{|l|}{ LN229: } \\
\hline Control & $1.102 \pm 0.012$ & $0.298 \pm 0.001$ & $1.400 \pm 0.011$ & $1.110 \pm 0.021$ & $0.760 \pm 0.020$ & $1.866 \pm 0.002$ \\
\hline $\mathrm{AA} 30 \mu \mathrm{g}$ & $1.427 \pm 0.035^{\star}$ & $0.271 \pm 0.006$ & $1.699 \pm 0.031^{*}$ & $1.410 \pm 0.083$ & $0.700 \pm 0.033$ & $2.116 \pm 0.100^{*}$ \\
\hline EPA $30 \mu g$ & $1.195 \pm 0.034^{*}$ & $0.404 \pm 0.002$ & $1.598 \pm 0.035^{\star}$ & $1.290 \pm 0.078$ & $0.766 \pm 0.076$ & $2.066 \pm 0.073^{*}$ \\
\hline \multicolumn{7}{|l|}{ HNGC2: } \\
\hline Control & $1.102 \pm 0.061$ & $0.282 \pm 0.006$ & $1.384 \pm 0.006$ & $1.216 \pm 0.031$ & $1.000 \pm 0.173$ & $2.216 \pm 0.082$ \\
\hline AA $30 \mu \mathrm{g}$ & $1.058 \pm 0.034$ & $0.249 \pm 0.007^{*}$ & $1.308 \pm 0.038$ & $1.050 \pm 0.037^{\star}$ & $0.717 \pm 0.049$ & $1.767 \pm 0.055^{*}$ \\
\hline EPA $30 \mu \mathrm{g}$ & $1.355 \pm 0.041^{*}$ & $0.406 \pm 0.002^{*}$ & $1.762 \pm 0.043$ & $1.116 \pm 0.048$ & $0.816 \pm 0.028$ & $1.933 \pm 0.031^{*}$ \\
\hline
\end{tabular}

B

\begin{tabular}{|c|c|c|c|c|}
\hline Parameter & $\begin{array}{c}\text { Catalase }\left[\mu \mathrm{M} \mathrm{H}_{2} \mathrm{O}_{2} /\right. \\
\text { min/gm protein] }\end{array}$ & SOD [U/mg protein] & $\begin{array}{l}\text { GST [ } \mu \mathrm{M} / \mathrm{min} / \\
\text { gm protein] }\end{array}$ & $\begin{array}{l}\text { GPX }[\mu \mathrm{M} / \mathrm{min} / \\
\text { gm protein] }\end{array}$ \\
\hline \multicolumn{5}{|l|}{ LN229: } \\
\hline Control & $9009.36 \pm 1358.9$ & $184.011 \pm 43.03$ & $18.144 \pm 3.325$ & $24503.38 \pm 2727.16$ \\
\hline AA $30 \mu g$ & $16404.15 \pm 2289^{\star}$ & $906.59 \pm 211^{*}$ & $68.80 \pm 16.42^{*}$ & $78451.58 \pm 22350.09$ \\
\hline EPA $30 \mu g$ & $9830.72 \pm 2870.25$ & $686.12 \pm 211.02$ & $38.02 \pm 6.67^{\star}$ & $23481.96 \pm 4937.79$ \\
\hline \multicolumn{5}{|l|}{ HNGC2: } \\
\hline Control & $9821.87 \pm 2287$ & $127.44 \pm 44.5$ & $18.23 \pm 4.94$ & $35106.08 \pm 1042.45$ \\
\hline AA $30 \mu g$ & $11565.24 \pm 2616$ & $393.75 \pm 85$ & $26.49 \pm 3.95$ & $60053.54 \pm 5906.215^{*}$ \\
\hline EPA $30 \mu \mathrm{g}$ & $1000.17 \pm 1693.52$ & $245.56 \pm 60.58$ & $19.60 \pm 0.79$ & $46316.38 \pm 4699.59$ \\
\hline
\end{tabular}

All values are expressed as mean $\pm S E M .{ }^{*} P<0.05$ - compared to control, AA - arachidonic acid, EPA - eicosapentaenoic acid.

decrease in $B C L-2 / B a x$ ratio (Figure $2 \mathrm{~A}$ ). In a similar fashion, AA/EPA produced a significant decrease in the expression of $N F-\kappa B / / \kappa B$ (Figure $2 \mathrm{~B}$ ), implying that $A A / E P A$ suppress inflammation. In contrast to these results, AA/EPA enhanced the expression of cytochrome $C$ and caspases 3 and 9 significantly in both the glioma cells (AA > EPA) (Figure $2 \mathrm{C}$ ) compared to the control.

$A A$ and EPA induced a significant decrease in the expression of $p 53$, Ras and Myc (except that $A A$ and EPA did not have any significant effect on Ras expression in HNGC2 cells, Figures $3 \mathrm{~A}$ and $\mathrm{B}$ ) in both the glioma cells compared to the control. In contrast, a significant increase in expression of Fos was seen in both LN229 and HNGC2 cells when exposed to AA and EPA (Figures $3 \mathrm{~A}$ and B), though HNGC2 cells when supplemented with EPA $30 \mu \mathrm{g} / \mathrm{ml}$ dose showed significantly decreased expression of Fos.

Neither of the glioma cells showed any change in COX-1 expression on exposure to AA and EPA. Ironically, COX-2 expression was significantly enhanced by AA and EPA in both the glioma cells. In contrast, the expression of 5-LOX was also signifi- cantly decreased in both the glioma cells by $A A$ and EPA in comparison to the control (Figure $3 \mathrm{C}$ ).

To understand and compare the effects of $A A$ and EPA on various indices studied in the present study on both the glioma cells, and their summary is depicted in Table II.

\section{Discussion}

Our results presented here suggest that both LN229 and HNGC2 glioma cells are sensitive to the growth inhibitory action of LA/GLA/AA and EPA/DHA (Figures $1 \mathrm{~A}$ and $\mathrm{B}$ ). These results are similar to those we obtained with IMR-32 cells [20]. LN229 cells showed greater sensitivity to the growth inhibitory action of PUFAs compared to HNGC2 cells. Despite the fact that the LOX inhibitor NDGA, but not indomethacin, a COX inhibitor, suppressed the proliferation of LN229 and HNGC2 cells in vitro, various prostaglandins and LTs tested showed only marginal growth suppressive action on LN229 and HNGC2 cells (data not shown). These results indicate that the growth inhibitory action of AA and EPA on LN229 and HNGC2 cells 
A

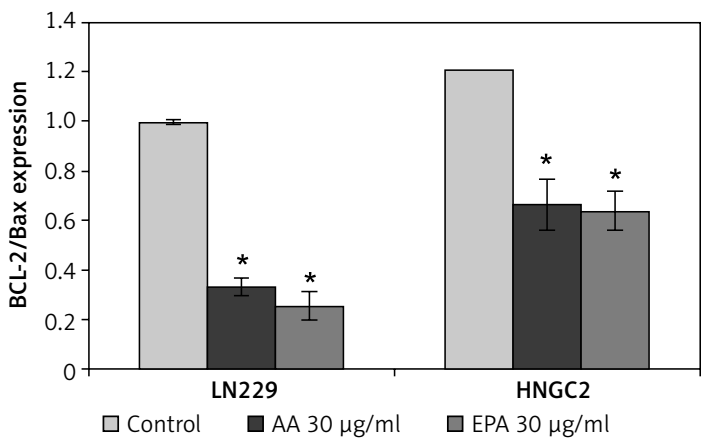

B

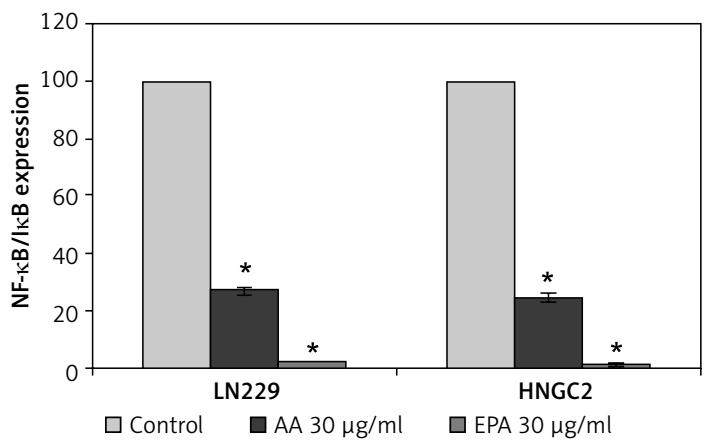

C

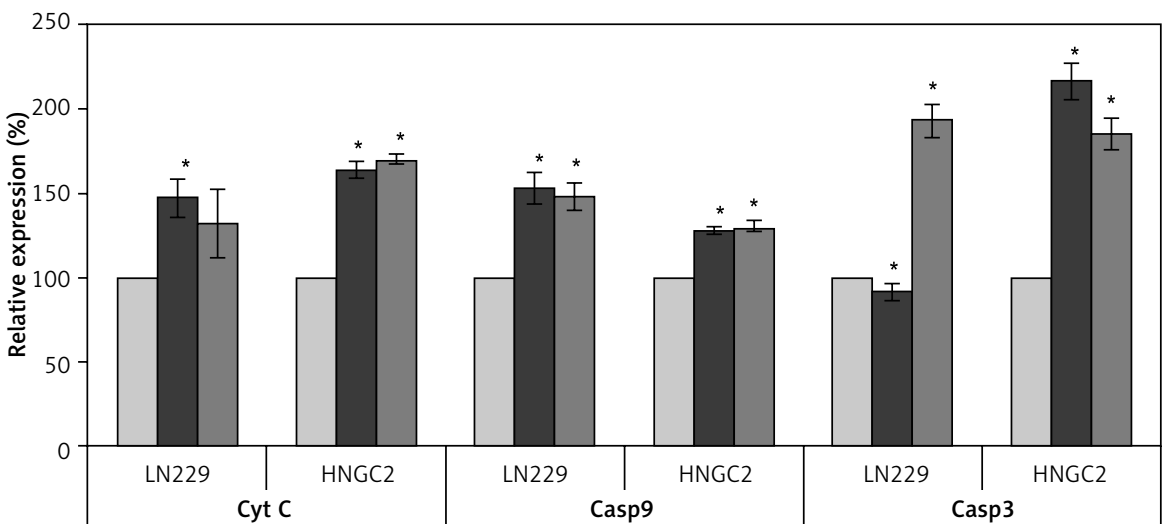

$\square$ Control $\quad \square$ AA $30 \mu \mathrm{g} / \mathrm{ml} \quad \square$ EPA $30 \mu \mathrm{g} / \mathrm{ml}$

Figure 2. Effect of $A A / E P A(30 \mu g / m l)$ on mRNA gene expression of $B c l-2-B a x$, inflammatory genes $N F-\kappa B / l \kappa B$ and apoptotic genes cyt C, casp9, casp3 in LN229 and HNGC2 cells. A - Expression of Bcl-2/Bax ratio in LN229 and HNGC2 cells. B - Expression of NF- $\kappa B / / \kappa B$ ratio in LN229 and HNGC2 cells. C - Expression of cyt C, caspase 9 and caspase 3 genes in LN229 and HNGC2 cells. The beta actin gene was loaded as a positive control

All values are expressed as mean \pm SEM. ${ }^{\star} P<0.05$ compared to control; $A A$ - arachidonic acid, EPA - eicosapentaenoic acid, CytC - cytochrome C, Casp9- caspase 9, Casp3-caspase 3.

may be due to the fatty acids themselves with little or no role for eicosanoids.

Further evaluation of the possible mechanism(s) of action of AA and EPA on glioma cells revealed that the $\mathrm{BCl}-2 / \mathrm{Bax}$ ratio (Bax is essential for apoptosis whereas overexpression of $\mathrm{BCl}-2$ enhances cell survival) was tilted more towards Bax (AA > EPA; LN229 > HNGC2), suggesting an increase in the rate of apoptosis (Figure $2 \mathrm{~A}$ ). The $\mathrm{BCl}-2 / \mathrm{Bax}$ ratio is much lower in EPA treated cells compared to AA treatment, which may explain why $A A$ is more effective than EPA in inhibiting the growth of LN229 compared to HNGC2 cells. Both $A A$ and EPA were almost equally effective in suppressing the $N F-\kappa B / / \kappa B$ ratio in both $L N 229$ and HNGC2 cells (Figure 2 B). In contrast, a significant increase in the expression of Fos was seen in both LN229 and HNGC2 cells when exposed to AA and EPA (Figures $3 \mathrm{~A}$ and $\mathrm{B}$ ), though HNGC2 cells when supplemented with EPA in a $30 \mu \mathrm{g} / \mathrm{ml}$ dose showed significantly decreased expression of Fos.

Neither of the glioma cells showed any change in COX-1 expression but showed significantly enhanced expression of COX-2 and 5-LOX by AA and EPA. These results could be interpreted to mean that glioma cells may produce more eicosanoids that do not have any significant action on their proliferation and thus reduce the intracellular concentration of toxic AA and EPA to avoid apoptosis. Furthermore, increased production of eicosanoids may enhance inflammation locally, which may augment glioma cell proliferation since inflammation has pro-carcinogenic action [22-24].

Overall, the most significant observation of the present study is an increase in the formation of lipid peroxides and $\mathrm{NO}$ and increased expression of cytochrome $C$ and caspases 3 and 8 (Figure $2 \mathrm{C}$, Table I) by AA and EPA in both the glioma cells examined. These results suggest that AA and EPA enhance the formation of lipid peroxides in tumor cells, which may result in an increase in the expression of cytochrome $C$ and caspases 3 and 8, leading to their apoptosis. Thus, AA and EPA induce apoptosis of glioma cells by activating both the extrinsic and intrinsic apoptotic pathways. A close examination of the results obtained in the present study suggests that the more the lipid peroxides generated in the tumor cells, the higher the concentrations of antioxidants and higher the rate of apoptosis (Figures 1 A, B, 2 C and Table I), 
A

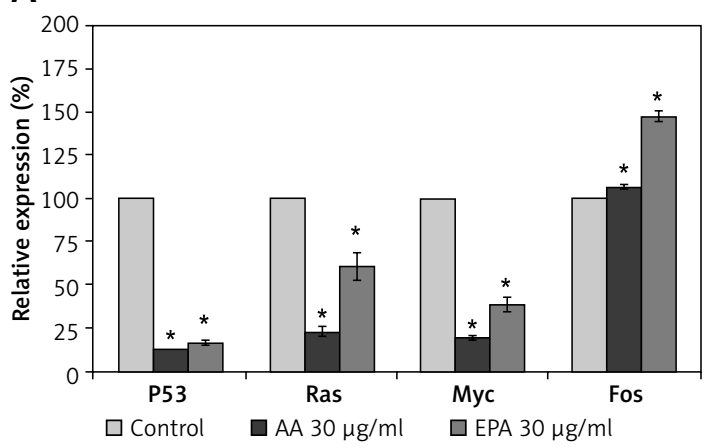

B

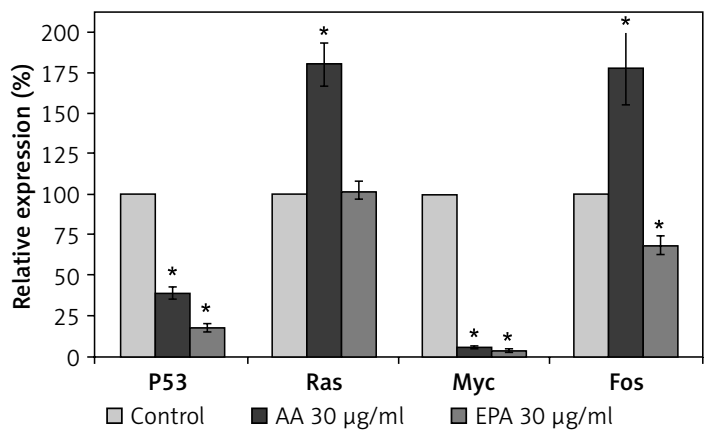

C

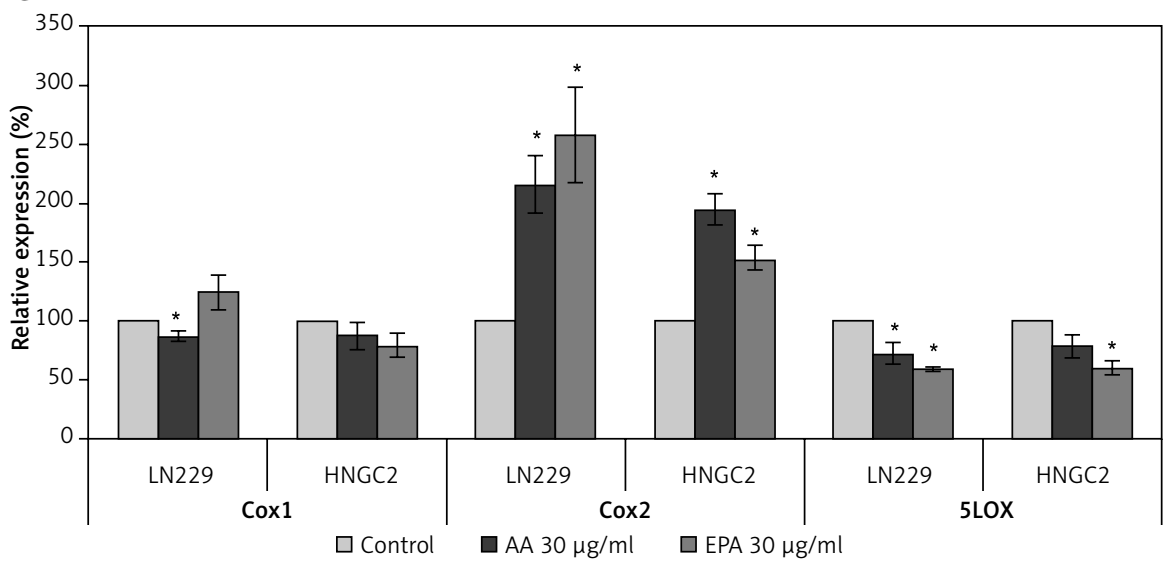

Figure 3. Effect of AA/EPA $(30 \mu \mathrm{g} / \mathrm{ml})$ on mRNA gene expression of oncogenes and metabolic genes COX-1, COX-2, 5-LOX in LN229 and HNGC2 cells. A - Expression of P53, Ras, Myc Fos, in LN229 cells. B - Expression of P53, Ras, Myc Fos, in HNGC2 cells. C - Expression of Cox1, Cox2 and 5LOX in LN229 and HNGC2 cells. The $\beta$-actin gene was loaded as a positive control. All values are expressed as mean \pm SEM. ${ }^{*} P<0.05$ compared to control. It may be noted here that there are no error bars for the controls in Figures 1-3 since we calculated the cell viability for the control group as $100 \%$. In these figures error bars for the control groups are not visible because we compared and calculated the control group values with the control group itself, so the error is the value ' 0 '. Also, the treated group values were compared and calculated with the control group values, resulting in error bars

C-control, AA - arachidonic acid, EPA - eicosapentaenoic acid

which suggests why AA is more potent than EPA in inducing apoptosis of LN229 cells compared to HNGC2 cells in vitro and LN229 cells show greater sensitivity to the growth inhibitory actions of $A A$ compared to HNGC2 cells. This may also explain the slightly higher expression of caspase 9 seen in LN229 cells compared to HNGC2 cells (Table II, though cytochrome $\mathrm{C}$ and caspase 3 expression levels are almost the same in both the glioma cells). Though we have not specifically investigated whether there is any direct correlation between lipid peroxides generated, degree of apoptosis and sensitivity of glioma cells to PUFAs, this interesting possibility needs to be evaluated in future studies. We aware of the limitations of the present study since we did not perform measurements of real-time PCR of p53, Ras, Myc, BCL-2/Bax, NF-кB/ $1 \kappa B$, and 5-LOX, FACS results of annexin and pi staining and Western blot of caspases to establish apoptosis of glioma cells on exposure to PUFAs. Despite this limitation, previously, we and others have shown $[1,2,8-13,16]$ that PUFAs indeed produce apoptosis of tumor cells on incubation with various PUFAs at the doses used in the present study, observations that support our present results and conclusions reached.

It is known that apoptosis is induced by the extrinsic death receptor pathway and the intrinsic mitochondrial pathway. Activation of caspases leads to the onset of apoptosis. Notably, both pathways converge at caspase-3, leading to activation of other proteases. The results of our study showed that in both the glioma cell lines, AA and EPA increased cytochrome $C$ and caspase- 3 and caspase- 9 but decreased the $\mathrm{BCl}-2 / \mathrm{Bax}$ ratio. Under normal physiological conditions, expression of Bax is increased in response to tumor suppressor protein p53, and Bax is involved in p53-mediated apoptosis. The p53 protein is a transcription factor, which is a part of the cell's response to stress and regulates many downstream target genes, including Bax. Apoptosis is regulated in part by the $\mathrm{BCl}-2$ gene, which promotes cell survival. Bax overexpression enhances apoptosis by 
Table II. Summary of effects of AA/EPA on various indices studied in glioma cells in vitro

\begin{tabular}{|c|c|c|c|}
\hline Fatty acid & Parameter & LN229 & HNGC2 \\
\hline AA & Cell proliferation & $\downarrow \downarrow \downarrow$ & $\downarrow \downarrow$ \\
\hline EPA & & $\leftrightarrow$ & $\downarrow \downarrow$ \\
\hline AA & $\mathrm{Bcl}-2 / \mathrm{Bax}$ & $\downarrow \downarrow \downarrow$ & $\downarrow \downarrow$ \\
\hline EPA & & $\downarrow \downarrow$ & $\downarrow$ \\
\hline $\mathrm{AA}$ & $N F-\kappa B / I \kappa B$ & $\downarrow \downarrow$ & $\downarrow \downarrow$ \\
\hline EPA & & $\downarrow \downarrow \downarrow$ & $\downarrow \downarrow \downarrow$ \\
\hline AA & Cytochrome C & 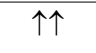 & 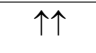 \\
\hline EPA & & 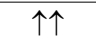 & १个 \\
\hline AA & Caspases 3 & $\uparrow \uparrow$ & $\uparrow \uparrow$ \\
\hline EPA & and 9 & $\uparrow \uparrow$ & $\uparrow \uparrow$ \\
\hline AA & P53 & $\downarrow \downarrow \downarrow$ & $\downarrow \downarrow$ \\
\hline EPA & & $\downarrow \downarrow$ & $\downarrow \downarrow$ \\
\hline AA & Ras & $\downarrow \downarrow \downarrow$ & १个 \\
\hline EPA & & $\downarrow$ & $\leftrightarrow$ \\
\hline $\mathrm{AA}$ & MYC & $\downarrow \downarrow \downarrow$ & $\downarrow \downarrow \downarrow$ \\
\hline EPA & & $\downarrow \downarrow$ & $\downarrow \downarrow \downarrow$ \\
\hline AA & FOS & $\uparrow$ & 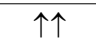 \\
\hline EPA & & 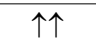 & $\downarrow$ \\
\hline AA & COX-1 & $\downarrow$ & $\leftrightarrow$ \\
\hline EPA & & $\leftrightarrow$ & $\leftrightarrow$ \\
\hline AA & cox-2 & 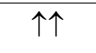 & 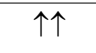 \\
\hline EPA & & 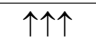 & 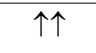 \\
\hline AA & 5-LOX & $\downarrow$ & $\leftrightarrow$ \\
\hline EPA & & $\downarrow \downarrow$ & $\downarrow \downarrow$ \\
\hline
\end{tabular}

the intrinsic pathway. Thus, the balance between $\mathrm{BCl}-2$ and $\mathrm{Bax}$ genes is an important determinant of apoptosis. In the present study, it is observed that $p 53$ expression and the $\mathrm{BCl}-2 / \mathrm{Bax}$ ratio were decreased (in other words, $B C l-2$ is decreased and $B a x$ is increased. i.e. relatively there is decreased expression of $\mathrm{BCl}-2$ and relatively higher expression of $B a x)$. It is known that p53 interacts with $B a x$, decreasing its activation to induce apoptosis. The results of the present study showed that both the glioma cell lines, when treated with $A A$ and EPA, showed decreased $p 53$ and Bax expression levels, which is contrary to the regulatory effect of $p 53$ on Bax. Generally, it is expected that $p 53$ has positive control of Bax expression, i.e. if $p 53$ expression is increased it leads to an increase in Bax expression as well. In contrast, in the present study, we noted the reverse, namely, a decrease in p53 expression but an increase in Bax expression. This suggests uncoupling of the relationship between $p 53$ and Bax expression.

Taking all the results of the present study into consideration, it is evident that $A A$ and EPA suppressed $p 53$, Ras, Myc, BCL-2/Bax, NF-кB/ $I_{\kappa} B$ and 5-LOX and enhanced cytochrome $C$ and caspases 3 and 9 expression and increased the accumulation of lipid peroxides and nitric oxide and altered their antioxidant defenses (LN229 $>$ HNGC2). These results suggest that possibly enhancement in the formation of lipid peroxides and consequent oxidative stress is responsible for the growth inhibitory action of AA and EPA and other PUFAs on glioma cells. These results are supported by our previous studies wherein we observed that AA induced apoptosis of IMR-32 cells, a human neuroblastoma cell line that is similar in characteristics to HNGC2 and LN229, by enhancing lipid peroxides and oxidative stress [20]. In the previous study [20] we noted that IMR-32 cells undergo apoptosis as a result of activation of the extrinsic apoptotic pathway due to the expression of Fas and caspases 8 and 3. In the present study, we did not study the expression of Fas and caspase 8 and so the involvement of the extrinsic pathway in the apoptosis of LN229 and HNGC2 cells remains conjectural.

In conclusion, it is known that caspases play a significant role in inflammation, cell proliferation, tumor suppression, cell differentiation, neural development and axon guidance and ageing [25] that may explain pleiotropic actions of AA and EPA and their metabolites [26, 27].

\section{Conflict of interest}

The authors declare no conflict of interest.

\section{References}

1. Das UN. Essential fatty acids enhance free radical generation and lipid peroxidation to induce apoptosis of tumor cells. Clin Lipidol 2011; 6: 463-89.

2. Das UN. Lipoxins, resolvins, protectins, maresins and nitrolipids and their clinical implications with specific reference to cancer: Part I. Clin Lipidol 2013; 8: 437-63.

3. Naidu MRC, Das UN, Kishan A. Intratumoral gamma-linolenic acid therapy of human gliomas. Prostaglandins Leukot Essen Fatty Acids 1992; 45: 181-4.

4. Das UN, Prasad VSSV, Reddy DR. Local application of gamma-linolenic acid in the treatment of human gliomas. Cancer Lett 1995; 94: 147-55.

5. Das UN. Gamma-linolenic acid therapy of human glioma - a review of in vitro, in vivo, and clinical studies. Med Sci Monit 2007; 13: RA119-31.

6. Reddy DR, Prasad VS, Das UN. Intratumoral injection of gamma-linolenic acid in malignant gliomas. J Clin Neurosci 1998; 5: 36-9.

7. Sandrone SS, Repossi G, Candolfi GM, Eynard AR. Polyunsaturated fatty acids and gliomas: a critical review of experimental, clinical, and epidemiologic data. Nutrition 2014; 30: 1104-9. 
8. Das UN. Tumoricidal action of unsaturated fatty acids and their relationship to free radicals and lipid peroxidation. Cancer Lett 1991; 56: 235-43.

9. Begin ME, Das UN, Ells G, Horrobin DF. Differential killing of human carcinoma cells supplemented with $\mathrm{n}-3$ and n-6 polyunsaturated fatty acids. J Natl Cancer Inst 1986; 77: 1053-62.

10. Madhavi N, Das UN. Effect of $n-6$ and $n-3$ fatty acids on the survival of vincristine sensitive and resistant human cervical carcinoma cells in vitro. Cancer Lett 1994; 84: 31-41.

11. Lu X, Yu H, Shen S, Das UN. Linoleic acid suppresses colorectal cancer cell growth by inducing oxidant stress and mitochondrial dysfunction. Lipids Health Dis 2010; 9: 106.

12. Abdi J, Garssen J, Faber J, Redegeld FA. Omega-3 fatty acids, EPA and DHA induce apoptosis and enhance drug sensitivity in multiple myeloma cells but not in normal peripheral mononuclear cells. J Nutr Biochem 2014; 25: 1254-62.

13. Skender B, Hofmanová J, Slavík J, et al. DHA-mediated enhancement of TRAIL-induced apoptosis in colon cancer cells is associated with engagement of mitochondria and specific alterations in sphingolipid metabolism. Biochim Biophys Acta 2014; 1841: 1308-17.

14. Lu XF, He GQ, Yu HN, Ma Q, Shen SR, Das UN. Colorectal cancer cell growth inhibition by linoleic acid is related to fatty acid composition changes. J Zhejiang Univ Sci B 2010; 11: 923-30.

15. Yu H, Liu Y, Pan W, Shen SR, Das UN. Polyunsaturated fatty acids augment tumoricidal action of 5 -fluorouracil on gastric cancer cells by their action on VEGF, TNF-alpha and lipid metabolism related factors. Arch Med Sci 2015; 11: 282-91.

16. Yu H, Shen Y, Ni X, Shen SR, Das UN. Polyunsaturated fatty acids trigger apoptosis of colon cancer cells through mitochondrial pathway. Arch Med Sci 2015; 11: 1081-94.

17. Hamamoto T, Suzuki K, Sasaki H, Ichikawa M, Kodama S, Watanabe M. Differences in effects of oncogenes on sensitivity to anticancer drugs. J Radiat Res 2005; 46: 197-203.

18. Gao XS, Asaumi J, Kawasaki S, et al. Sensitivity of anticancer drugs in NIH3T3' cells transfected with oncogenes accompanied by pSV2neo vector, Anticancer Res 1995; 15: 1911-4.

19. Sailaja P, Mani AM, Naveen Kumar GV, Anasuya Devi H, Siresha B, Das UN. Effect of polyunsaturated fatty acids and their metabolites on bleomycin-induced cytotoxic action on human neuroblastoma cells in vitro. PLoS One 2014; 9: e114766.

20. Sailaja P, Dwarakanath B, Das UN. Arachidonic acid activates extrinsic apoptotic pathway to enhance tumoricidal action of bleomycin against IMR-32 cells. Prostaglandins Leukot Essen Fatty Acids 2018; 132: 16-22.

21. Guchelaar HJ, Vermes A, Vermes I, Haanen C. Apoptosis: molecular mechanisms and implications for cancer chemotherapy. Pharm World Sci 1997; 19: 119-25.

22. Arwert EN, Lal R, Quist S, Rosewell I, van Rooijen N, Watt FM. Tumor formation initiated by nondividing epidermal cells via an inflammatory infiltrate. Proc Natl Acad Sci USA 2010; 107: 19903-8.

23. Mantovanai A. Inflaming metastasis. Nature 2009; 457: 36-7.

24. McLean MH, Murray GI, Stewart KN, et al. The inflammatory micro environment in colorectal neoplasia. PLoS One 2011; 6: e15366.
25. Shalini S, Dorstyn L, Dawar S, Kumar S. Old, new and emerging functions of caspases. Cell Death Differentiation 2015; 22: 526-39.

26. Das UN. Arachidonic acid in health and disease with focus on hypertension and diabetes mellitus. J Adv Res 2018; 11: 33-41.

27. Das UN. Ageing: is there a role for arachidonic acid and other bioactive lipids? A review. J Advanced Res 2018; 11: 67-79. 